ARTÍ́CULO ORIGITHL

\title{
Causas estructurales y coyunturales de la Independencia Hispanoamericana en la Historiografía
}

\author{
Structural and short-term causes in Spanish-American Independence in Historiography
}

${ }^{1}$ Florentino Arpa Calachua

ORCID: 0000-0002-2152-8707

\section{RESUMEn}

En las conmemoraciones del bicentenario de la independencia de los pueblos latinoamericanos, es importante conocer las explicaciones sobre las causas de su desarrollo y sus vinculaciones complejas. En la mayoría de los casos, las investigaciones identifican causas de orden interno y externo, sin considerar las relaciones existentes entre ellas. La propuesta de la investigación sobre las causas de la independencia ha permitido agruparlas en estructurales y coyunturales. Las primeras (las causas estructurales) nos permiten reconocer los cambios de larga duración que ya enfrentaba la humanidad al aproximarse al siglo XIX. En lo económico, el sistema feudal rivalizaba con el sistema capitalista; en lo político, las potencias de ultramar se enfrentaban por el dominio del mundo conocido; en lo social, las clases sociales enfrentaban serias contradicciones; en lo ideológico, el cambio del pensamiento teocéntrico al antropocéntrico terminó en un cuestionamiento del mundo existente. Las segundas (las causas coyunturales) son aquellas que aceleran y sacan a flote la crisis existente entre los años 1805 a 1814. Esta crisis se agudiza con la derrota de la flota española en Trafalgar en 1805, que permitió el control e influencia de Inglaterra en la economía y política de las colonias hispanoamericanas; otra causa fue la invasión napoleónica a España en 1808, que originó un vacío de poder, que fue aprovechado por las provincias españolas en el nuevo mundo. Considerar las causas estructurales y coyunturales dentro del quehacer de la historia permitirá realizar las vinculaciones de dichas causas con las locales, permitiendo una adecuada interpretación histórica.

Palabras clave: Causas coyunturales, causas estructurales, Hispanoamérica, Independencia

\section{ABSTRACT}

It is important to know the explanations about the causes of Latin American peoples, development and complex connection in commemoration of their Bicentenary independence. Research identifies causes of internal and external order in most cases, without considering the current relationship between them. The research proposal about the independence causes has allowed to group them into structural and short-term causes. Structural causes allow us to recognize long term changes which humanity had already faced as the nineteenth century approached.

${ }^{1}$ Dirección de Educación Básica para Estudiantes de Desempeño Sobresaliente y Alto Rendimiento (DEBEDSAR). Colegio de Alto Rendimiento (COAR). Tacna, Perú. E-mail:flarpa@minedu.gob.pe 
Economically, the feudal system was competing with the capitalist system; politically, the overseas powers were confronting each other for the domination of the known world; in the social aspect, the social classes were facing serious contradictions; ideologically, the change from theocentric to anthropocentric thinking led to a questioning of the existing world. The second (short-term causes) are those ones which accelerate and brought to light the crisis that existed between 1805 and 1814. This crisis worsened with the defeat of the Spanish fleet in Trafalgar in 1805, which allowed the control and influence of England in the economy and politics of the Spanish-American colonies; another cause was the Napoleonic invasion of Spain in 1808, which originated a power vacuum, which was harnessed by the Spanish provinces in the New World. Considering the structural and short-term causes within the work of history will allow to carry out the connection between them with the local ones enabling the proper historical interpretation.

Keywords: Shor-term causes, structural causes, Spanish American, Independence

\section{INTRODUCCIÓN}

El objetivo del presente trabajo es ordenar y jerarquizar las causas del proceso de independencia latinoamericano en la historiografía. Esto permitirá aclarar qué factores causales deben abordarse en investigaciones de historias nacionales y regionales de los países latinoamericanos. Resulta imperativo que la historiografía presente una metodología de ordenación y jerarquización de los elementos causales, para lograr una comprensión del surgimiento del proceso de independencia hispanoamericano.

Una serie de perspectivas históricas nos han permitido tener una diversidad de elementos causales del proceso de independencia hispanoamericana, considerándose, en algunos casos, como acontecimientos aislados y regionales, sin tener en cuenta la geopolítica internacional y el poder de los países hegemónicos, en su lucha por el dominio y control mundial. Considerar las relaciones causales de dominio mundial y los intereses locales, aprovechados de manera estratégica, serán de mucha importancia para conocer cómo hasta el día de hoy esas disputas por el control mundial permanecen latentes, quizás los Estados hayan dado paso a las nuevas formas del poder empresarial.

La revisión de una serie de documentos históricos sobre las causas de la independencia nos presenta de forma constante una relación secuencial y lineal de los procesos siguientes: revolución de las Trece Colonias, Revolución Francesa y como resultado natural: la independencia de Hispanoamérica. Este esquema simple es seguido por la historiografía regional. Las nuevas propuestas historiográficas exigen un abordaje completo y complejo, considerando las interacciones entre las historias locales y los procesos externos, involucrando a los diversos actores sociales, considerando la particularidad de cada espacio geográfico. Nuestro deseo es aportar con la historia local, señalando una ruta que nos permita encontrar las complejas relaciones de los factores que intervienen en el proceso de independencia hispanoamericana.

Nuestra investigación plantea la siguiente pregunta para el debate: ¿Hasta quépunto se puede ordenary jerarquizar las causas del proceso de independencia latinoamericano en la historiografía? Para nosotros existe la posibilidad de una ordenación y jerarquización, siguiendo la propuesta metodológica de la historia crítica.

\section{MATERIALES Y MÉTODOS}

El método utilizado en la presente investigación es el histórico estructural, que permite una aproximación dialéctica al tiempo histórico-social de estudio. Lo primero, es entender que el devenir histórico no es un simple agregado lineal de sus componentes individuales, sino, un sistema complejo con múltiples interacciones. El método utilizado permitirá una "reconstrucción articulada" de los procesos históricos, logrando una síntesis ordenada y jerarquizada. Esta ordenación se sustenta en las interconexiones sociales que dan origen a las estructuras globales fundamentales en la sociedad: económico, político, social y cultural, los que a su vez se subdividen en estructuras menores y relaciones complejas. 
La investigación hará una revisión sobre el tratamiento lineal o complejo de las causas que llevaron a los países a la lucha por la independencia. En este trabajo, no ahondaremos en las tendencias historiográficas, pero somos conscientes que existe una relación directa entre el tratamiento del hecho histórico y la tendencia historiográfica que defiende cada historiador.

La técnica empleada es la revisión documentaria. La muestra analizada para nuestra investigación, se constituye de publicaciones de libros y artículos de la red, en revistas indexadas que tengan un tratamiento sobre las causas de la independencia y que correspondan a países latinoamericanos. La mayoría de los textos elegidos son cercanos a las conmemoraciones, debido a que estas fechas permiten profundas reflexiones conmemorativas, sin embargo, muchos de ellos están focalizados en temas diversos de balance y la publicación documentaria en archivos digitales.

El instrumento utilizado corresponde al sistema de fichaje de cada una de las obras consultadas, dentro de las que podemos destacar las fichas textuales, de resumen y de síntesis.

\section{RESULTADOS Y DISCUSIÓN}

En las fuentes analizadas se observa una diversidad de métodos y tendencias históricas, que han logrado agrupar las causas, de manera reiterativa, en causas directas o más importantes, haciendo un análisis unilateral de la historia. Los investigadores en historia mencionan que las causas más comunes son: el proceso de maduración de la conciencia nacional, la influencia externa y la rivalidad de las grandes potencias de la época.

Pardo (2009), en su trabajo Bicentenario de la independencia de Colombia. Causas de la independencia bispanoamericana y de Colombia, hace una división tradicional de las causas en: causas de las independencias latinoamericanas y causas de la independencia del Nuevo reino de la Nueva Granada, la que subdivide en causas externas e internas. A pesar que se recoge la conclusión del congreso hispanoamericano de historia "Causas y características de la independencia Hispanoamérica", no se logra una interrelación adecuada de las causas. La conclusión del congreso señala que: "La revolución americana no es un episodio aislado cuya explicación no deba buscarse en la brusca actuación de una o varios causas concretas, sino un proceso espiritual complejo, vinculado a la bistoria universal (...)”. Resulta interesante que se destaque esta conclusión, pero que en la práctica investigativa no se encuentre su aplicabilidad.

De igual forma, Cavagnaro (2006), en su obra Materiales para la historia de Tacna, señala que la historiografía de mediados del siglo XX explicaba la independencia bajo la influencia de factores externos, posteriormente las interpretaciones señalaban a la independencia como un proceso interno de maduración de las fuerzas internas y/o externas que desarrollaron la conciencia de los pobladores. Señala, además, que una nueva corriente historiográfica inglesa y norteamericana formula la influencia externa desde las rivalidades de las grandes potencias, que impactaron en la vida de los habitantes de las colonias españolas (p. 11). En su obra, además, se menciona una serie de factores de diversos autores (Valega, Madariaga, Cardoso, Spalding y Bonilla), pero no se observa una correlación de las causas planteadas.

De la Puente (2001), en su ensayo sobre La historiografía peruana sobre la independencia en el siglo XX, identifica un tradición en la interpretación de la independencia, señalando que esta obedece a "La madurez de cada reino, el espiritu crítico y de protesta, la voluntad de introducir reformas sociales y políticas, la adhesión al territorio del propio nacimiento, el progresivo afán por conocer y al mismo tiempo querer la memoria de cada reino y la memoria común americana; todas estas ideas y actitudes se manifestaron en uno u otro ambiente del imperio" (p. 16). Esta es la tradición que ha logrado una fuerte influencia en la historiografía local y continental.

Orrego, Aljovín y López (2009), en su ensayo La independencia en el Perú y otros países, señala como causa de la independencia a la crisis de la monarquía española entre 1808 y 1826, producto de la invasión napoleónica, no solo para el Perú, sino también para Venezuela, Colombia, Ecuador, Bolivia, Brasil y Argentina. El trabajo centra su interpretación en acontecimientos locales a partir de la crisis española, sin considerar la influencia de otros elementos. 
Rinke y Schulze (2010), en su trabajo Los orígenes de las revoluciones de independencia de América Latina en perspectiva atlántica, señalan a las causas internas como principales en el desarrollo de la independencia, reconociendo el impacto decisivo que los acontecimientos externos tuvieron en el proceso. "Si bien la circulación del saber transatlántico constituye un factor de gran significación, las rebeliones locales a fines del siglo XVIII manifiestan la importancia y la influencia del contexto local en este proceso".

Otros historiadores agrupan las causas en exógenas y endógenas. Los defensores de las causas exógenas han enfatizado sus trabajos en los siguientes factores:

- Los movimientos intelectuales (la ilustración o la iluminación) surgidos en Francia en el siglo XVIII.

- La lucha de las potencias, especialmente Inglaterra y Francia.

- El enfrentamiento ideológico que se dio en España entre reformistas y fidelistas en la segunda mitad del siglo XVIII hasta el siglo XIX.

- La errada política impuesta por España a sus colonias americanas.

- La intervención de Inglaterra con la apropiación de la isla Trinidad en la desembocadura del Orinoco que fue depósito de provisiones revolucionarias.

- La independencia de las trece colonias norteamericanas en 1776.

- La revolución industrial en Gran Bretaña (1750).

- La agitada política y las guerras europeas en el período 1792-1815.

- La influencia de las asociaciones laicas, especialmente la francmasonería.

- La obra desarrollada por los jesuitas en pro de la independencia, como respuesta al vejamen sufrido por parte de la corona española.

Los defensores de las causas endógenas de la independencia enfatizan en la formación de una conciencia nacional del pueblo mestizo como causa primordial; el surgimiento de la burguesía americana y las demás causas son factores coadyuvantes.

Breña (2010), en su ensayo Las independencias americanas, la revolución española y el enfoque atlántico, reconoce la importancia de la rivalidad entre las potencias europeas de fines del siglo XVII e inicios del XIX. De igual forma, la presencia de la independencia de las Trece Colonias y la Revolución Francesa que estuvo presente en el imaginario de los españoles americanos durante la independencia. Este enfoque coloca al proceso de independencia hispanoamericano como una parte de la secuencia de revoluciones. El autor señala que: "Desde la perspectiva de la «revolución atlántica», las revoluciones hispánicas tienden a ser vistas como un ejemplo más de un movimiento ideológico-político de largo aliento que surgió en el ámbito atlántico hacía, digamos, 1775, y que se cerró, digamos también, en 1825". Según Breña, el proceso de independencia hispanoamericano no es el resultado de un contagio doctrinal o ideológico de las revoluciones de 1776 y 1789, tampoco son una lucha contra el monarca español, sino todo lo contrario. Menos aún se considera como un proceso de maduración intelectual social fundamentado en la ilustración. Para el autor, el proceso de independencia hispanoamericano "es el producto de una ocupación, que se transformó en invasión y finalmente en imposición de un monarca extranjero en el trono de la monarquía católica". En esta última afirmación, se puede observar la contradicción en el pensamiento político y religioso entre España y Francia. Coincidimos con Breña en reconocer que los elementos de la historia atlántica aportan en la contextualización, pero debemos profundizar en las características particulares de la independencia hispanoamericana.

En la clásica obra La independencia en el Perú, Bonilla, Chaunu, Halperín, Hobsbawm, Spalding y Vilar (1972) ya señalaban que el tratamiento de las causas de la independencia se hacía considerando los factores internos y externos, sin encontrar una dinámica entre ellos. De estos dos factores el que más destacaba era la influencia del exterior en el proceso de independencia. Para los autores no existía relación entre lo que la historia escribía y las acciones de sus protagonistas, además de no tomar en cuenta la complejidad social y 
económica de los espacios geográficos involucrados. En su última actualización Metáfora y realidad de la independencia en el Perú, Bonilla (2016) señala que "La independencia es un proceso continuo y concatenado. Lo que quiere decir que no se puede entender nada de lo que ocurrió si uno no empieza a mirar desde el norte hasta el sur, por ejemplo. Tampoco se puede entender lo que ocurrió en América Latina si uno prescinde de lo que ocurrió en el otro lado del Atlántico" (p.18). Además de lo señalado anteriormente, el autor enfatiza en la nueva propuesta historiográfica centrado en el papel que desempeñan las clases populares en el proceso de independencia, de igual forma en las fuerzas internacionales y domésticas. También señala el rumbo de las investigaciones hacia las causas y consecuencias de la crisis colonial e independencia.

No se puede negar que las observaciones antes señaladas tienen vigencia hasta hoy en los estudios del proceso de independencia de esta región del planeta. La propuesta historiográfica exigida debe integrar las historias de los diferentes espacios geográficos y sus actores sociales. Sobre la participación de las clases populares una nueva tendencia historiográfica se hace presente, denominada historia social, pero que aún no ha logrado filtrarse en la historia nacional, por lo menos en el Perú. Walker (2008) señala que esto se debe a una exageración de la naturaleza insurgente de las comunidades campesinas y el temor a la determinación significativa de los movimientos políticos regionales y/o campesinos en términos nacionales, lo que presenta una historia negativa, de brechas, desigualdades y fracasos.

La revisión bibliográfica realizada, hasta el momento, nos permite observar dos cuestiones fundamentales. La primera, que la historiografía tradicional ha mantenido una visión lineal y desarticulada del proceso de independencia hispanoamericana. La segunda, que existe un llamado a realizar una historia bajo otros parámetros metodológicos, que abarque no solo las historias locales, sino que estas se vinculen a las historias de otras naciones. Además de considerar a los protagonistas de las diferentes clases sociales. Lo que permitiría que la población actual se vea reflejada en su historia.

El trabajo de Chust (2007) coincide con nuestro planteamiento y recoge la interpretación de Rodríguez sobre la independencia de Hispanoamérica, señalando que es un proceso de grandes cambios y transformaciones en el siglo XVIII-XIX: "Proceso de cambio que hay que contextualizarlo con varias trasformaciones interrelacionadas, generales y particulares, en el contexto del tránsito al capitalismo: la emergencia de la burguesía como clase social dominante, la revolución industrial británica, la reestructuración de los imperios ibéricos, la diversidad regional y, haciendo bincapié, la revolución burguesa en España que comenzó con las Cortes de Cádiz". Para Basadre (1971), "La historia es un proceso motivado por fuerzas bumanas al que hay que entender a través de términos puramente humanos. (...) Su destino alberga un enjambre de causas diversas, coyunturas, estructuras, avances y retrocesos y fenómenos con elementos eventuales de sorpresa" (p.1055). Chust y Basadre concuerdan en señalar que la construcción histórica debe considerar diversos elementos causales entrelazados de forma compleja en su generalidad y particularidad.

Por esta razón, consideramos que partiendo de un análisis histórico estructural, la independencia tuvo dos bloques de causas: las estructurales y las coyunturales (Vitale, II, 1997), sin dejar de interrelacionarse.

\section{Causas estructurales}

Para Pomian, mencionado por Casali (2007), una estructura "sería el armazón que sostiene imperceptiblemente los acontecimientos, siendo las estructuras una realidad que pervive silenciosamente por año y siglos, sin que se constate cómo influyen en el movimiento de los acontecimientos, siendo a veces, dirá, especies de cárceles que atan las vivencias de los individuos". De esta definición se desprende la razón del descuido en su estudio. Los aportes de Braudel sobre los tiempos históricos permitirán un entendimiento adecuado de las estructuras, como un proceso de larga duración en la historia.

Estas relaciones suficientemente "fijas" en el tiempo (denominadas estructuras, en el lenguaje de los historiadores) las encontraremos en los aspectos económicos, sociales, políticos e ideológicos. Las causas estructurales representan las condiciones adecuadas para que las causas coyunturales puedan desarrollarse sin ningún problema. Todo intento de querer explicar un acontecimiento histórico regional, sin considerar las estructuras históricas, resultará fallido.

La Vida y la Historia, Vol. 8, N. ${ }^{\circ}$ 1, pp. 43-52 (2021) 


\section{Causa de estructura económica}

El sistema feudal español no estaba en condiciones de soportar el desmesurado crecimiento demográfico y económico, producto de la primera revolución industrial en progreso. "España nunca pudo garantizar a los criollos un comercio permanente, ni de exportación ni de importación. Su industria era incapaz de satisfacer la creciente demanda de las colonias, hecho que inducia al contrabando. Tampoco podía absorber la producción colonial en ascenso" (Vitale, 1997, p. 6). Fueron varios problemas los que tenía que enfrentar el sistema económico feudal español. El primero estaba referido a la absorción de la producción económica, la oferta superaba largamente a la demanda interna de la economía, lo que impulsó la búsqueda de nuevos mercados externos. El segundo, que se vincula al primero, tiene que ver con el creciente comercio internacional que necesitaba abrirse, de par en par, al mundo de la época. Este mercado debía ser sin restricciones, contrario al comercio monopólico practicado por los reinos hegemónicos. El tercero, fue como una consecuencia de los dos anteriores, que se vinculan a las restricciones existentes, producto del monopolio comercial que acrecentaron, de manera progresiva, el tráfico ilegal de mercancía. Mientras el sistema económico feudal no pudiera resolver estos problemas estructurales, seguirían siendo el caldo de cultivo de otros problemas. Por lo tanto, un sistema económico que no respondía a la cambiante dinámica de los consumidores y productores, se aproximaba de manera voraz a un capitalismo destructivo del que hoy somos víctimas. El sistema imperante tendría un colapso en el mediano o corto plazo de la historia.

\section{Causa de estructura social}

Sin dejar de lado la cuestión anterior, es necesario recordar que la economía es producto de la interacción humana; y por lo tanto, son las clases sociales motivadas por intereses las que promueven el devenir económico. El desarrollo industrial dio origen y empoderamiento a la burguesía, como nueva clase social, que inexorablemente desplazaría a la nobleza feudal. "Esa clase social emergente estaba constituida por los terratenientes y comerciantes nativos. [Quienes] Controlaban a fines de la colonia las principales fuentes de riqueza, aunque el gobierno seguia en manos de los representantes de la monarquia" (Vitale, 1997, p. 5). Como lo señala Vitale, el poder económico estaba en manos de la clase emergente (burguesía) y el poder político en la clase tradicional (nobleza), cada una de ellas con intereses que se encontraban contrapuestos. Los primeros necesitaban un sistema de libre comercio para ampliar sus mercados y los segundos, mantener el monopolio comercial, esto en el nivel de los productores. Desde el nivel de los consumidores, la clase acomodada reclamaba diversidad de productos y los sectores menos acomodados exigían la reducción de impuestos. La clase emergente ambicionaba el poder político, porque este le permitiría tener control de las aduanas, los estancos, las rentas fiscales, los cargos públicos y el ejército. Esta condición generaría nuevas relaciones sociales de asimetría entre los peninsulares y colonos, de igual forma la asimetría social se vería reflejada entre los propios colonos. Esta búsqueda por el poder y control económico agudizaron las relaciones sociales entre la nobleza y la burguesía, entre colonos y peninsulares.

\section{Causa de estructura política}

En este acápite es necesario señalar el juego de la geopolítica internacional, que tiene como actores principales a España, que hegemonizaba el mundo y los aspirantes, Inglaterra y Francia, quienes lucharán por el poder mundial. Desde mediados del siglo XVIII, Francia se enfrentaba a Inglaterra con el apoyo de España durante la Guerra de los Siete Años (1757-1763). El vencedor de esta guerra fue Inglaterra con la firma del Tratado de París (1763). Sin embargo, la lucha por la hegemonía mundial no se detendría. España y Francia derrotarán a Inglaterra en la guerra de independencia de las 13 colonias norteamericanas en 1776. Inglaterra se cobrará la revancha apoyando en la independencia de las colonias españolas en América. Como se puede observar, las relaciones de política internacional determinarán los desenlaces de las guerras coloniales. La lucha por la hegemonía internacional es una causa estructural que no se considera como tal, por la mayoría de los historiadores, sin embargo, resulta interesante hacer el análisis de la geopolítica internacional para entender cómo se mueven las piezas en el tablero de ajedrez. Con lo señalado 
anteriormente, se puede establecer que el proceso de independencia se circunscribía también a las rivalidades de las potencias del momento.

\section{Causa de estructura ideológica}

Un elemento causal que no debemos olvidar es la transición en el pensamiento. Nos encontramos, en la época de estudio, en el paso de un pensamiento teocéntrico a uno antropocéntrico basado en la razón, denominado de manera genérica como ilustración.

Este movimiento intelectual no surge de la noche a la mañana, sino que tiene un desarrollo a lo largo del tiempo. Son las fuerzas productivas y la lucha de clases que se expresaron finalmente en la consolidación de una propuesta que permitió un ideario común contra el sistema feudal, inicialmente para reformularlo y posteriormente para cambiarlo completamente.

Tomaremos como punto referencial el humanismo, que representa la oposición a la escolástica, posteriormente el desarrollo del renacimiento que es el nacimiento de la ciencia como hoy la conocemos y como punto culminante la ilustración, que se convierte en el instrumento ideológico que permite el cuestionamiento al sistema feudal.

La ilustración, que tiene su fundamento en la razón, pretendió unificar y direccionar un tejido de acontecimientos (descubrimientos geográficos, batallas políticas, innovaciones filosóficas y revoluciones tecnológicas) en una nueva visión humana y social. Esta visión de "desarrollo racional" tuvo dos vertientes: una que fue utilizada como instrumento "racional" de sujeción y control; y la otra perseguía "racionalizar" el mundo social hasta llegar a una sociedad de justicia y bienestar, la primera denominada ilustración y la segunda iluminismo.

El iluminismo hispánico tuvo características muy particulares, las luces no apuntaban directamente a una crítica del sistema feudal, sino al reconocimiento de los problemas internos dentro del mismo sistema y su intención fue buscar soluciones a esas contradicciones internas para revitalizar y fortalecer el sistema. Esa tal vez fue la razón por la que no impulsaron el desarrollo industrial, siendo una potencia con poder económico. Los españoles estuvieron concentrados en resolver sus problemas internos, para aliviar las tenciones de la lucha de clases, proteger a su clase dominante y reprimir a su clase emergente. Estas medidas permitirían la búsqueda de una sociedad sin tensiones en su interior, propósito que no se logró debido al desarrollo del comercio humano y el aniquilamiento de grupos humanos, producto de la expansión mercantil, sustentada en el racionalismo cartesiano. La balanza ya se había inclinado en 1550-51 con la de derrota de Bartolomé de las Casas por Juan Ginés de Sepúlveda en la Junta de Valladolid.

La ilustración inglesa se ve impulsada por el desarrollo de la revolución industrial, que intenta justificar la explotación de la mano de obra y los recursos naturales sin medida ni control alguno, colocando al hombre como dueño de la naturaleza y de otros hombres. Adam Smith sintetiza la doctrina económica liberal con amplitud y sustenta las exigencias y aspiraciones de los principales agentes económicos de la época, lo que "(...) modifica los supuestos ideológicos, las creencias, las formas de vida de la sociedad a lo largo de varios siglos, y que alcanza un desarrollo incontenible en el siglo XVIII, habría de reflejarse en las formulaciones politicas y filosóficas de ese siglo, y en los avances de la ciencia y la tecnología" (Flores, 1999, p. 114). La ilustración inglesa será el pensamiento que se irradiará en el mundo y modificará paulatinamente el pensamiento de pobladores de la época. Por lo tanto, no podemos dejar de considerar la transición del pensamiento como un elemento causal vinculado a los grandes cambios materiales que se encuentran en desarrollo en el continente europeo y alcanzan entendimientos diversos en Latinoamérica.

\section{Causas coyunturales}

Para Osorio (1998), se habla "de coyuntura cuando nos referimos al nivel más inmediato de la realidad social, el espesor de superficie, y a un segmento de tiempo corto especifico, aquél en el que se condensa el tiempo social. Una coyuntura, por lo tanto, es un cruce entre aquellas dos dimensiones de la totalidad social'. En otros términos, podemos señalar que las 
coyunturas son hechos históricos ocurridos en un tiempo relativamente corto en un espacio geográfico determinado. En una coyuntura se puede observar cómo los procesos profundos y de larga duración se visibilizan en el corto tiempo. También podemos señalar, que las causas coyunturales son aquellos acontecimientos que precipitan o aceleran las causas estructurales. Para nuestro análisis, señalaremos dos causas coyunturales que sacarán a flote la crisis del sistema feudal.

\section{La derrota de la flota española en Trafalgar (1805)}

En el año de 1805, la escuadra franco-española es destruida por la marina inglesa en la batalla naval de Trafalgar, colocando a España sin control naval sobre sus colonias americanas.

La victoria de Inglaterra le otorga el dominio marítimo y por lo tanto la posibilidad de desarrollar el comercio sin ningún tipo de restricciones. Por otro lado, las colonias españolas quedaron aisladas de la metrópoli, afectando seriamente a su comercio internacional y los ingresos de su clase productora.

Este hecho dejó el camino abierto para que Inglaterra pueda ingresar y comerciar con las colonias españolas, esta intromisión no solo sería en cuestiones económicas, sino también en cuestiones políticas. Inglaterra no fomentó de manera directa las ideas democráticas y el desarrollo económico en América del sur, debido a la experiencia recientemente vivida con sus trece colonias, sin embargo, utilizó estratégicamente a sus diplomáticos para obtener beneficios de las colonias hispanoamericanas, ya que no podían dominarlas de manera directa.

Una de las primeras acciones que realizó fue eliminar a los revolucionarios con ideas republicanas y federales de los gobiernos juntistas, además de ser personajes que fomentaban un desarrollo interior, propuesta que resultaba desventajosa para los ingleses. El caso del Río de la Plata y las disputas entre saavedristas y morenistas es una muestra palpable de ello (Choy, 1979).

Una vez dominada la mayor red de comercio de la época, Inglaterra manipuló e influyó en la política interna de las colonias hispanoamericanas.

\section{Las invasiones napoleónicas a España en 1808}

La causa coyuntural más importante que desencadena el proceso de independencia de las colonias hispánicas fue la invasión napoleónica a España, que no representaba simplemente las ambiciones de Napoleón Bonaparte, sino la lucha entre la burguesía inglesa y francesa. Este acontecimiento desembocará en la formación de los gobiernos juntistas entre 1808 y 1814.

La invasión napoleónica ocasionó un vacío de poder tras las abdicaciones de Bayona de los reyes Carlos IV y Fernando VII. En ambos lados del Atlántico el rechazo a los franceses fue unánime. Este hecho fue el catalizador del movimiento juntista. La crisis política generó un amplio debate sobre varias cuestiones. Un primer punto fue determinar la condición de las colonias americanas. ¿Tenían los mismos derechos que una provincia peninsular? Lo cierto es que se les reconoció sus derechos (Cuenca, 1994). Con este reconocimiento quedaban autorizadas para la constitución de juntas de gobierno. La pregunta que surge de inmediato es: ¿Por qué el ejército español luchó contra las juntas de gobierno, si estas respaldaban al rey Fernando VII?

Una junta de gobierno desconocía la autoridad del virrey, puesto que este ya no podía representar a un rey inexistente. La élite privilegiada estaba convencida de que la creación de una autoridad autónoma contrariaba la autoridad de la metrópoli. Por esta razón, comerciantes y terratenientes de prestigio y caudal económico fueron los que dirigieron el movimiento contra la iniciativa juntista.

El temor de la élite privilegiada no estaba errado del todo. Los movimientos juntitas canalizaron las demandas de la población y en algunos casos, los reclamos fueron aprovechados como parte de un proceso para consolidar ideas de autonomía administrativa, que desembocaría finalmente en la idea por la independencia.

Como se puede observar, la invasión napoleónica fue el catalizador de una serie de acontecimientos políticos que agudizaron la crisis ya existente, sobre las demandas de las diferentes clases sociales. 


\section{CONCLUSIONES}

La bibliografía escrutada nos señala que existe una especie de confusión en la aproximación a los factores causales del proceso de independencia hispanoamericano en la historiografía local y continental. En la mayoría de los casos, se formula un listado completo de las causas clasificadas en internas y externas, pero no se observa la correlación necesaria para poder categorizar y jerarquizar los elementos causales. En algunos trabajos se destaca la necesidad de esta interrelación como propuesta válida, que merece ser formulada dentro de la investigación histórica nacional y regional.

De esta forma, a manera de propuesta, se ha logrado ordenar y jerarquizar los factores causales del proceso de independencia. La propuesta metodológica inicia con la ordenación y agrupación de las causas en estructurales y coyunturales. El paso siguiente es la jerarquización de las causas señaladas, considerando lo estructural como macroproceso y lo coyuntural como microproceso, en otras palabras, lo coyuntural se subordina a lo estructural. Posteriormente, las causas coyunturales deben considerarse como catalizadores de una serie de eventos en los diferentes espacios geográficos y sus clases sociales.

No se podría entender el desencadenamiento de sucesos histórico coyunturales, si no tenemos presente las causas estructurales. Dentro de las mismas condiciones de reestructuración y cambio del orden económico, político, social e ideológico, se fueron desarrollando situaciones particulares en diferentes lugares de dominación hispánica en América del sur.

Para lograr una comprensión de las causas de la independencia de las colonias hispanoamericanas, es necesario tener presente que las causas estructurales son procesos de larga duración que pasan inadvertidos por la población de la época, pero que los historiadores pueden identificar y analizar de manera adecuada.

La propuesta desarrollada ha permitido la ordenación de las causas en estructurales y coyunturales de orden económico, político, social e ideológico y la jerarquización de las estructuras y coyunturas, que se retroalimenta de manera constante. En lo económico, es importante estudiar el proceso de cambio del sistema feudal al sistema capitalista; en cuanto a lo político, la rivalidad de los reinos de ultramar por dominar el orden económico; en el aspecto social, las contradicciones entre las clases sociales por mantener el poder político y económico; en el plano ideológico, el cambio de mentalidad de un pensamiento teocéntrico a uno antropocéntrico, dominado por la razón. Estos cambios en la estructura de la sociedad europea y americana remecieron el mundo conocido de la época.

Dentro de las causas coyunturales, se ha logrado identificar dos acontecimientos que permitieron expresar la crisis del sistema. El primero es la derrota de la flota española en Trafalgar en 1805, que dejó el camino abierto para que Inglaterra pueda influir en la economía y política de las colonias hispanoamericanas; el segundo es la invasión napoleónica a España en 1808, que generó un vacío de poder, que los españoles intentaron resolver con el movimiento juntista. Sin embargo, esta iniciativa despertó la inquietud por la autonomía y la posterior independencia de los pueblos americanos dominados por los españoles.

Para finalizar, queremos agregar que las conmemoraciones por el bicentenario de la independencia han permitido profundas reflexiones sobre nuestro pasado y presente, además de promover la investigación histórica bajo nuevas metodologías y perspectivas. El trabajo presentado identifica acciones por realizar sobre la investigación histórica, que debe ser holística y transdiciplinar, considerando la participación de los sectores populares, para llegar a un entendimiento real de la historia, que identifique al poblador actual con su pasado, que es el punto de partida para la construcción de una ciudadanía responsable. 


\section{REFERENCIAS}

Basadre, J. (1971). Introducción a las bases documentales para la bistoria de la república del Perú con algunas reflexiones. Lima: Ediciones PLV. IEP.

Bonilla, H. (2016). Metáfora y realidad de la independencia en el Perú. Lima: Instituto de Estudios Peruanos

Bonilla, H., Chaunu, P., Halperín, T., Hobsbawm, E., Spalding, K., \& Vilar, P. (1972). La Independencia en elPerú. Lima: Instituto de Estudios Peruanos IEP.

Breña, R. (2010). Las independencias americanas, la revolución española y el enfoque atlántico. Historia y Política, (24), 11-22. https:/ / dialnet.unirioja.es/servlet/articulo?codigo=3322761

Casali, A. (2007). Una adaptación del estructuralismo a la historia. La larga duración histórica.: Clave metodológica de las diferentes temporalidades. Analecta: revista de bumanidades, (2). https://dialnet.unirioja.es/descarga/articulo/2603201.pdf

Cavagnaro, L. (2006). Materiales para la historia de Tacna. Emancipación (1780-1821). Tomo V. Tacna: EDPYME "CREAR TACNA".

Choy, E. (1979). Antropología e Historia. Lima: Empresa Editora Humboldt.

Chust, M. (2007). La independencia en Hispanoamérica. Reflexiones, revisiones y cuestiones. Anuario de Historia Regionaly de las Fronteras, 12 (1), 385-414. https:/ / www.redalyc.org/articulo.oa?id=407539686015

Cuenca, J. (1994). Enciclopedia de historia universal. América prehispánica y colonial: del despotismo ilustrado (s. XVIII) a los nacionalismos (s. XIX). México: Editorial Océano.

De la Puente, J. (2001). La historiografía peruana sobre la independencia en el siglo XX. En S. O'Phelan Godoy, Laindependencia del Perú (págs. 11-27). Lima: Instituto Riva Agüero.

Flores, V. (1999). Crítica de la globalidad. Dominación y liberación en nuestro tiempo. México D.F.: Fondo de Cultura Económica.

Orrego, J., Aljovín, C., \& López, J. (2009). Las independencias desde la perspectiva de los actores sociales. Lima: Organización de Estados Iberoamericanos.

Osorio, J. (1998). Estructuras, sujetos y coyuntura: desequilibrios y arritmias en la historia. Iztapalapa: Revista de Ciencias Sociales y Humanidades, ( 4 ), $13-28$. https://dialnet.unirioja.es/servlet/articulo?codigo $=7055796$

Pardo, Y. (2009). Bicentenario de la independencia de Colombia. Causas de la independencia bispanoamericana y de Colombia. Via Inveniendi Et Iudicandi, 5(1), 163-182. https:// doi.org/10.15332/s1909-0528.2010.0001.05

Rinke, S., \& Schulze, F. (2010). Los orígenes de las revoluciones de independencia de América Latina en perspectiva atlántica. Estudos Ibero-Americanos, 36 (2), 153-178. https://www.redalyc.org/pdf/1346/134618607003.pdf

Vitale, L. (1997). Historia social comparada de los pueblos de América Latina. Independencia y formación social republicana. Siglo XIX, Tomo II. http://www.quedelibros.com/autor/1056/Vitale-Luis.html

Walker, C. (2008). La nueva historia y la historia de siempre: el impacto de las nuevas corrientes historiográficas en el Perú actual. En Aguirre, C. \& Evoy, C. Intelectuales y poder (págs. 479-510). Lima: Instituto Francés de Estudios Andinos. 